\title{
Semi-automatic LiDAR point cloud denoising using a connected-component labelling method
}

\author{
Ján KAŇUK, Jozef ŠUPINSKÝ, Ján ŠA ŠAK, Jaroslav HOFIERKA, \\ Yongbo WANG, Qiuzhao ZHANG, Vladimír SEDLÁK, \\ Katarína ONAČILLOVÁ, Michal GALLAY
}

\begin{abstract}
The Smart City concept requires new, fast methods for collection of 3-D data representing features of urban landscape. Laser scanning technology (LiDAR - Light Detection and Ranging) enables such approach producing dense 3-D point clouds of millions of points, which, however, contain noise. Therefore, we developed a new approach allowing for a semi-automatic elimination of data noise resulting from motion of objects within the scanned scene such as persons. We used a connected-component labelling method to filter out the noise points from terrestrial laser scanning point clouds. Our approach was based on a step-by-step object classification with a proper parameterisation. In the first step, all points located close to the predicted terrain were selected. In the second step, the points representing the terrain and floor were classified using the surface filter tool implemented in the RiScan Pro software by RIEGL. The rest of points were classified using point cloud clustering via the connected-component labelling method implemented in the CloudCompare software. In the final step, the operator manually decides whether the point cluster represents the noise. The method was applied to the Cathedral of Saint Elizabeth, a sacral object located in the historical centre of the city of Košice in Slovakia during normal operating hours. We managed to capture approximately $80 \%$ of the data noise in total. The method provides a better flexibility in surveying overcrowded city locations using the laser scanning technology.
\end{abstract}

Keywords: point cloud filtration, terrestrial laser scanning, LiDAR, noise elimination, connected-component labelling, Smart City

\section{Introduction}

3-D city models are an immanent part of the Smart City concept (Yang and Lee 2019). Creating a digital database of 3-D buildings currently exploits mainly the remote sensing methods (Bonczak and Kontokosta 2019, Luo et al. 2019, Onačillová and Kaňuk 2016), such as laser scanning (Moon et al. 2019) and digital photogrammetry based on structure-from-motion (Martinez-Carricondo et al. 2019). Laser scanning technology (LiDAR) is one of the main methods used for mapping to build a complex 3-D geodatabase on the national level in many states across the world (Novo-Fernández et al. 2019, Monnet et al. 2016) and also in Slovakia (Fraštia et al. 2019). LiDAR enables highly detailed 3-D mapping and digital modelling of terrain, buildings, vegetation canopy, technical infrastructure, etc. (Yang et al. 2019). Many kinds of man-made objects in a city require specific approach for capturing their complex surface morphology (Amoruso and Salerno 2019). In addition to administrative, industrial, economic or military-strategic buildings, buildings belonging to the material cultural heritage also constitute a specific category in this context and, therefore, they are an integral part of the 3-D smart city database (Fryskowska and Stachelek 2019).

DOI: https://doi.org/10.33542/GC2019-2-08 
The main goal of high-detailed 3-D mapping of the cultural heritage objects is not only to protect and document them for future generations, but also to make them accessible to the general public through interactive 3-D visualizations (Boutsi et al. 2019, Thwaites et al. 2019). For these reasons, it is necessary to record external and internal parts of cultural heritage objects in ultra-high spatial resolution (Monego et al. 2019). The restoration of the Notre Dame cathedral after it got severely damaged by fire provides a vivid example of how 3-D mapping of such historical objects in high resolution can help (Martin 2019).

Combining terrestrial and airborne data acquisition methods such as laser scanning and digital photogrammetry (Fritsch and Klein 2018) is generally used in high-detailed 3-D mapping of cultural heritage buildings. This is justified, because it is not possible to capture all parts of the mapped object by ground-based collection methods. Usually, an unmanned aerial system (UAS), which can be equipped by a payload such as laser scanner or camera, is used to map the roof parts of the buildings (Kaňuk et al. 2018). Subsequently, the mapping is performed so that the entire object is mapped as much as possible and the unsampled locations are minimized, either by remotely-controlled or by software-planned manoeuvers. Given the current legislation, the use of UASs for building mapping in most countries of the European Union is considerably limited and requires a relatively demanding torture of administrative tasks in both the preparatory and post-processing phases (Cracknell 2017). Also, during the flight, it is necessary to provide the entire mapping area so that no persons are present in the site. If a UAS flight is carried out inside a building, the mapping area must also be closed.

Sacral objects of cultural heritage, such as churches or cathedrals are usually located in the centre of towns and, due to their location, there is a high incidence and movement of persons in their immediate vicinity or inside. In addition, cathedral interiors are used for regular worship ceremonies. During the day, they are attended by believers for a prayer or by tourists. To capture the exterior and interior parts of cathedrals in ultra-high resolution (spatial resolution of the objects is $0.01 \mathrm{~m}$ ), the mapping is usually done by closing the object during mapping so that there are no persons in the mapping location. Besides, to ensure security during mapping, the main reason for closure is that persons in the area of interest during mapping (whether static or dynamically moving) create physical barriers, thereby reducing the coverage of the record by the sensor used. All unwanted objects (or persons in this context) represent noise in the resulting 3-D point cloud, which needs to be removed in the post-processing phase. On the other hand, closing the building for public causes considerable complication to the building normal use and imposes new administration requirements to carry out of the mapping.

In the case of mapping a cathedral by terrestrial laser scanning technique, the administrative effort in the preparatory phase is much simpler. One of the strengths of this technology is that it is a contactless and fast mapping method, produces almost no disturbing noise emissions, and does not impose increased movement of operators that could have a negative impact on normal cathedral operation. On the other hand, the problem of terrestrial laser scanning is persons who, in the resulting cloud points, are sources of high noise. Moreover, ground methods do not allow for surveying parts of the cathedral that are not in the direct line of sight from the scanner point of view. These gaps in roofing coverage can be partially compensated by aerial laser scanning data available from a nationwide database.

The aim of the presented paper is to develop and verify a gradual semi-automatic classification of point cloud from laser scanning based on the connected component labelling method in order to eliminate noise. The noise in the data in our case study comprises visitors' point representations as well as stray points that arise as reflections from glass objects. The innovation of the paper is also in the presented procedure for mapping and creating 3-D models of sacral objects belonging to the material cultural heritage by a combination of terrestrial and airborne laser scanning. The scanning was performed in full operation of the cathedral without closing it. To add a colour texture from the photos to the resulting model, it was necessary to perform mapping in good light conditions during the day. In this paper, we demonstrate the 
method of collecting and processing 3-D point clouds from various devices and their placement in a uniform coordinate system for the purpose of creating a 3-D model of the cathedral in ultra-high spatial resolution.

\section{Study area}

The Cathedral of St. Elizabeth located in the historical centre of the city of Košice (Fig. 1) was selected for the demonstrating the process of semi-automatic classification of point cloud from laser scanning using the connected component labelling method. It is a national cultural monument, which, together with the adjacent buildings (Urban Tower and St. Michael's Chapel), have been listed as national cultural heritage since 1970 .

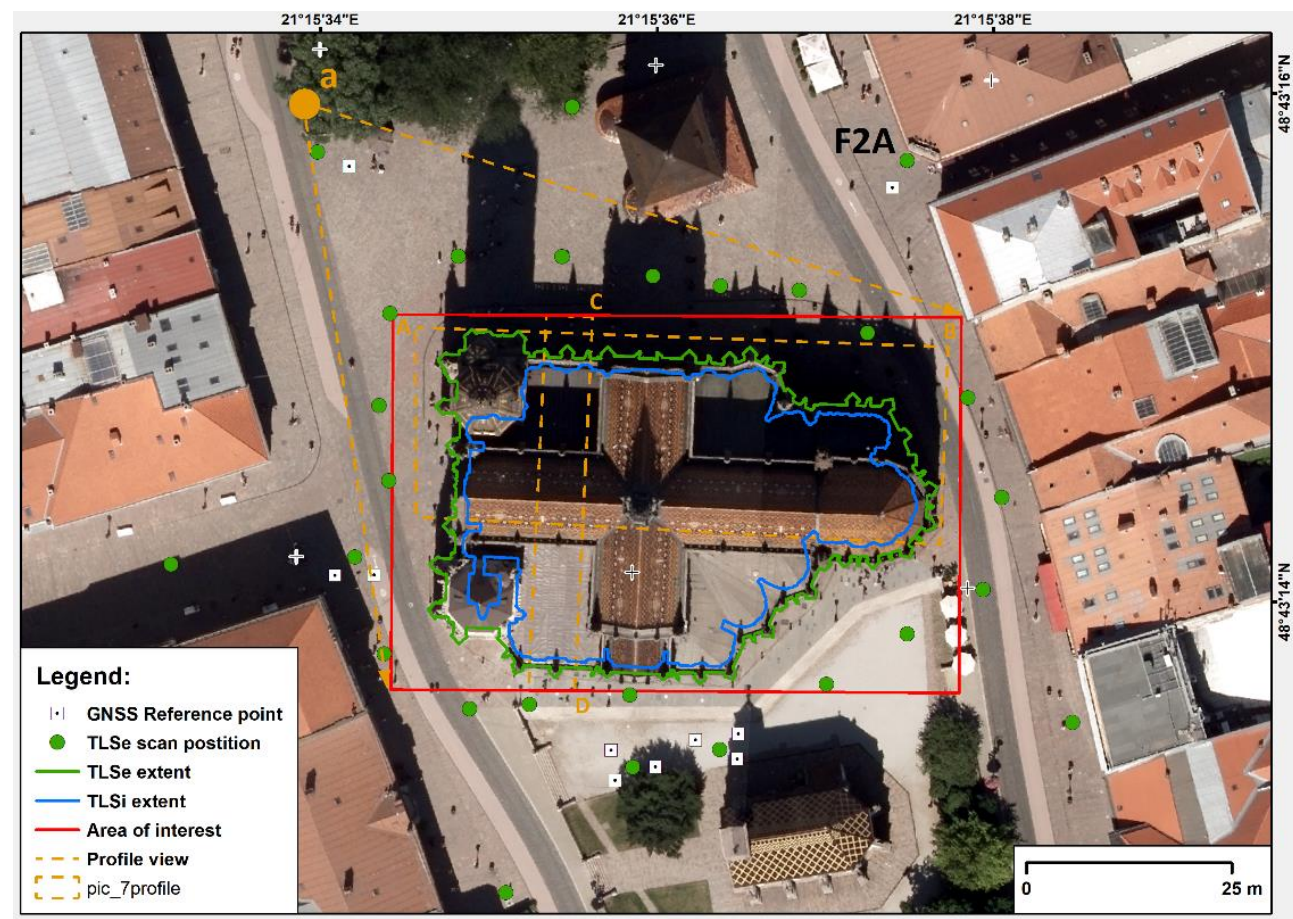

Fig. 1. Location of the Cathedral of St. Elizabeth in the city centre of Košice. The red line shows the Area of Interest that was mapped. Using a terrestrial laser scanning, the exterior walls of the cathedral (green line) with the immediate surroundings as well as the interior, the outline of which is shown by the blue line, have been mapped in detail. The scanner positions (green dots) have been placed in the exterior to capture all the niches and wall, as well as the turrets and part of the roof visible from ground. For placement point clouds in a uniform coordinate system, ground control points (GCPs, white squares with a black dot in the centre) were used around the cathedral and near the scan positions. The orange dashed lines are the section views and profiles of the object marked with the letters $A / B$ and $C / D$, where we demonstrate the results in Fig. 8 and Fig. 9 and a position labelled " $a$ " indicating field of view for perspective portray in Fig. 5 and Fig. 10.

The cathedral is the dominant object of the historical city centre for its unique architectural design and central location on the main street. It has an important historical-artistic value, as it was built in the style of High Gothic period. The architectural importance of this monument is also enhanced by the fact that it is the most eastern localized Gothic cathedral in Europe. 
Originally, a single nave cathedral began to be built at the end of the $13^{\text {th }}$ century, which ground plan is essentially identical to the main nave of the today's cathedral. After the fire of the cathedral in 1378, the construction of a new part of the cathedral began, the shape of which we know today (Fig. 2a, 2b). For financial reasons, the construction was suspended at the beginning of the $16^{\text {th }}$ century.

Later, the cathedral underwent several reconstructions, while its Gothic style remained preserved. The cathedral was caught several times by fires (the biggest fire was in 1556), which mainly affected the interior of the cathedral. The history of the cathedral was studied by several authors (e.g., Cidlínska 1975, Vaško et al. 2000, Žáry 2011).

Although the interior parts of the cathedral are morphologically complex, their disposition is compact (Fig. 2b). The main navy (Fig. 4. j) is crossed by the transverse one (Fig. 4. k) of the same height and width, creating a shape of the cross. The ends of the individual navies are terminated by the main altar and three richly decorated portals (Fig. 4. c, d, e), which are also easily recognizable from the exterior. The main navies are linked with four other side navies, which create a voluminous central space, which is divided by massive pillars. The cathedral includes two chapels (Fig. 4. f, g), sacristy (Fig. 4. h) and a chorus with organ (Fig. 4. i). In the interior of the cathedral are located several Gothic panel paintings, frescoes, sculptures, several side altars with paintings and sculptures from different periods, crypts and sarcophagi and other objects of high historical, social and cultural value.

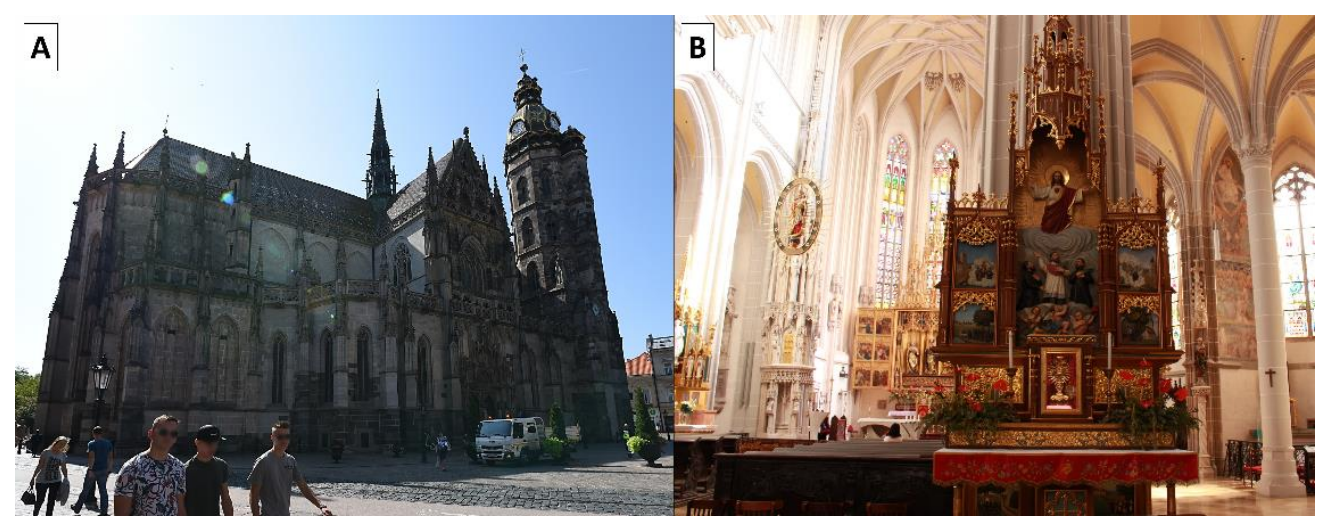

Fig. 2. (a) View of the northern portal of the Cathedral of St. Elizabeth (Fig. 4. d) from the junction of Hlavná Street and Mlynská Street during the scanning mission (Fig. 1). The outer wall of the cathedral and the roof is morphologically complex. Next to the northern portal is the northern tower, also known as the Žigmud's Tower (Fig. 4. a); (b) View of the cathedral interior. In the foreground is the altar of Three martyrs from Košice, in the background is the main altar of St Elizabeth (Fig. 4. l). The interior of the cathedral is also morphologically complex, the individual parts are separated by massive pillars and columns.

\section{Data and methods}

The aim of the complex 3-D modelling of the cathedral was in capturing the exterior and interior in ultra-high spatial resolution for which we defined the workflow shown in Fig. 3. In this paper, we use the term 3D model in ultra-high resolution for a 3D model which smallest mapping unit is $0.01 \mathrm{~m}$. The data collection involved airborne and terrestrial laser scanning. Ground mapping was carried out in agreement with the parish office during the standard operation of the cathedral on two days from 08:00 to 15:00. During this time, people were moving freely in the cathedral, thus they were captured by scanning introducing noise in the LiDAR point clouds. The mapping was avoided during the morning Holy masses and after 3:00 pm during the cathedral's afternoon program. 


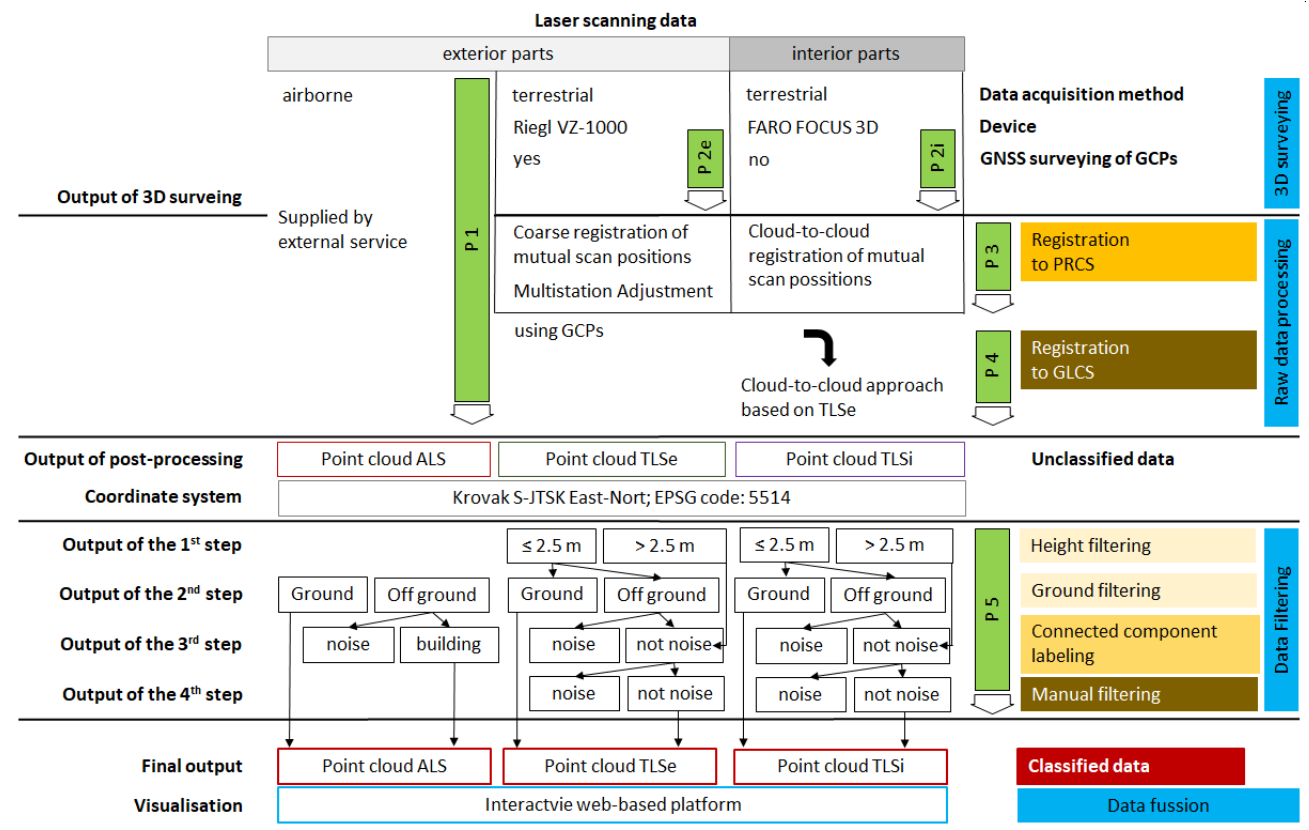

Fig. 3. Flowchart showing the methodological procedure for data acquisition, processing, classifying and integrating data representing the Cathedral of St. Elizabeth into an interactive web-based platform. Meanings of used abbreviations: GNSS - global navigation satellite system, GCPs - ground control points, PRCS - project coordinate system, GLCS - global coordinate system, ALS - airborne laser scanning, TLSe - terrestrial laser scanning of exterior, $T L S i$ - terrestrial laser scanning of interior;

\section{3-D surveying and raw data processing}

Three different sensors were used to acquire the 3-D point representation of the cathedral. For modelling the top parts of the building, an existing airborne laser scanning data was provided by an external supplier. The mapping was performed by the Leica ALS70 laser scanner in combination with the Leica RCD30 imaging camera system in September 2016. There were 18 flight lines with 355 images taken. The Leica RCD30 is a medium-format digital imaging system, from which images were used to colourize the LiDAR points with RGB natural colours. The flight altitude was at $1,000 \mathrm{~m}$ above the ground, achieving an average point density of 13.66 points $/ \mathrm{m}^{2}$ with $500 \mathrm{kHz}$ laser pulse repetition rate. In this paper, we want to verify the approach of combining terrestrial and aerial laser scanning for generation of a 3-D model of the cathedral for 3-D. The airborne LiDAR point cloud was supplied in the national coordinate system S-JTSK (EPSG code: 5514). The advantage of the airborne viewing geometry was in capturing the roof elements of the cathedral, but the facades were mapped sparsely (Fig. 5. A). The classification of data from airborne laser scanning is due to mapping techniques and resulting density of point cloud well elaborated by many authors (Li et al. 2019, Pirotti et al. 2019, Ullrich and Pfennigbauer 2019) and implemented in multiple software (Badenko et al. 2019). In our case study, we classify ALS data with LAStools software using the lasground and lasclassify tools. The final ALS point cloud was classified into three categories as ground, building and noise.

Therefore, terrestrial laser scanning was used to map the exterior facades and the interior of the cathedral. To reduce mapping time, we decided to use 2 different types of scanners. The adjacent exterior surroundings of the cathedral including the cathedral facades was surveyed by our VZ-1000 terrestrial laser scanner by Riegl with integrated Nikon D810 camera for colourizing the point cloud (Fig. 3, P2e). The maximum scanning range was set to $450 \mathrm{~m}$ allowing for $300 \mathrm{kHz}$ pulse repetition rate, which reduced the time of scanning while increasing the density 
of spatial sampling. In total, the scanning in the exterior was performed from 27 positions (Fig. 1) and more than 410 million of points were recorded (Tab. 1). After scanning, individual scan positions were registered (Fig. 3, P3) in two steps. The first step was a coarse registration process in which individual scan positions were placed into a common, so called project, coordinate system (PRCS) using at least 4 identical points for each pair of scan positions by their manual identification and selection. In the next step, the mutual orientation of the scans was improved by an automatic registration procedure using a patch filter method (Ullrich et al. 2003) was used with the multistation adjustment (MSA) tool implemented in the RiSCAN Pro software by Riegl similarly as described in Šašak et al. (2019) and Šupinský et al. (2019). Normal vectors of the generated planes with a minimum of 10 points and a maximum points amplitude from the detected plane of $0.01 \mathrm{~m}$ were automatically derived from the individual scan positions. The final standard deviation error of registration of mutual scan positions was $0.0057 \mathrm{~m}$. The resulting point cloud of the cathedral exterior and the raw data post-processing is shown in a Fig. 5. B.

The interior of the cathedral was scanned by a FARO FOCUS 3-D X130 HDR terrestrial laser scanner in ultra-high resolution. The digital photo camera was also activated during scanning by which the points were assigned natural colours in RGB codes. Given the complex morphology of the cathedral interior and ensuring sufficient overlap between the individual scans, 58 scan positions had to be placed inside the cathedral (Fig. 4) by which the main nave (Fig. 4. j), transverse nave (Fig. 4. k), the four side navies, presbytery with the altar (Fig. 4. l) and the sacristy (Fig. 4. h) were successively mapped. Also two side chapels (Fig. 4.f, g), stairs to the choir (Fig. 4. b) and the organ itself were scanned (Fig. 4. i). More than 1.6 billion points were recorded during the TLSi (Tab. 1).

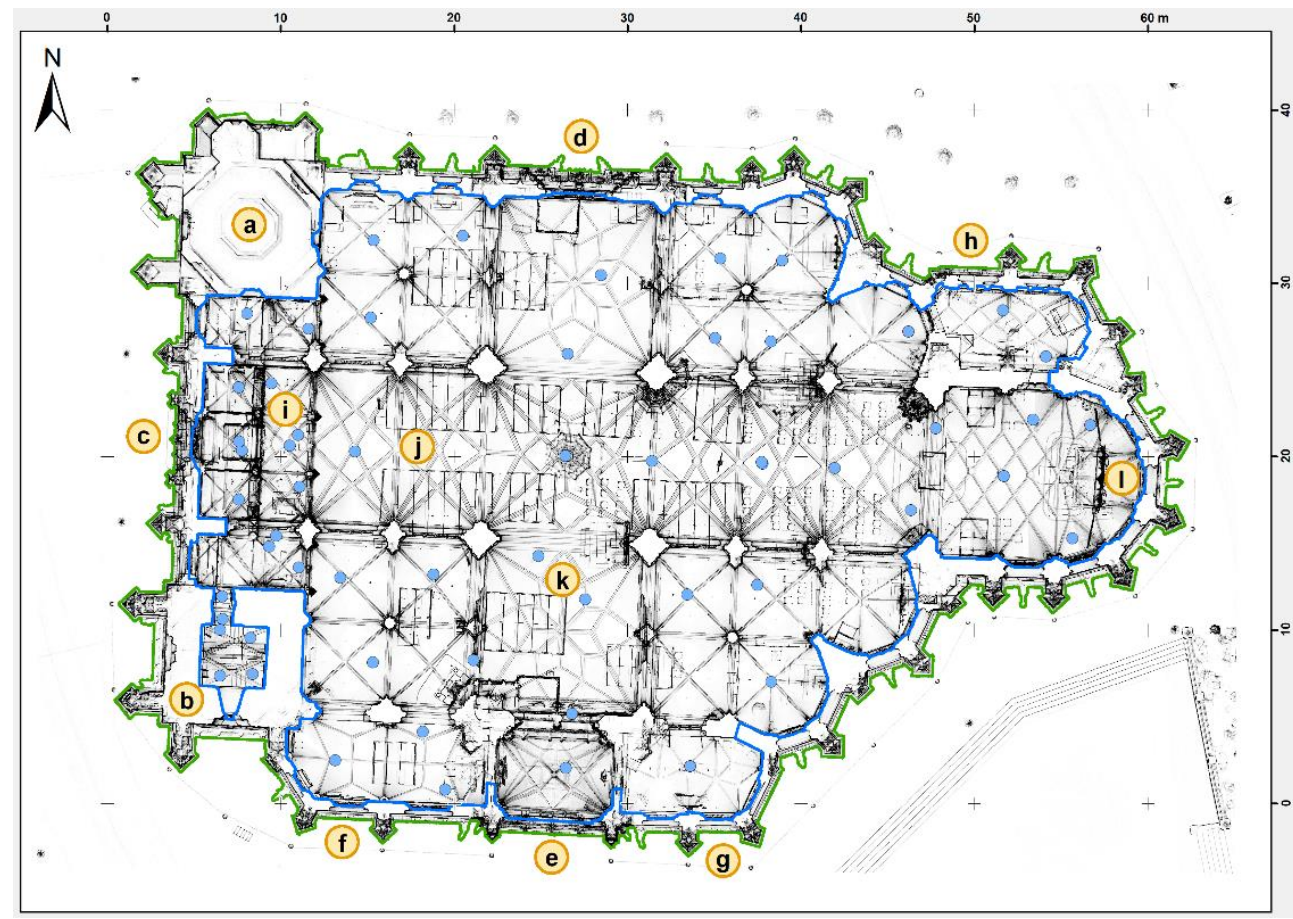

Fig. 4. The disposition of space of the cathedral containing (a) the north (Žigmund) tower, (b) the south (Matej's) tower, (c) the western portal, (d) the northern portal, (e) the southern portal, $(f)$ the Mettercie's chapel - the Annunciation of the Virgin Mary, $(g)$ the Chapel of the Holy Cross, $(h)$ the sacristy, ( $i)$ the choir with the organ, $(j)$ the main nave, $(k)$ the transverse nave, and $(l)$ the presbytery with the main altar. The blue circles locate the scan positions. The blue line represents the inner and green the outer wall of the cathedral. 
Mapping was performed without using any targets which considerably saved time required for scanning. The inclinometer, barometer, and compass during the scanning mission, which facilitated automatic registration of mutual scan positions in PRCS, were turned on. Internal registration of individual scan positions was performed in the Scene software by FARO using a combination of Top view and Cloud-to-Cloud registration methods. The resulting standard deviation error of mutually orienting individual scans in a common PRCS was $0.00175 \mathrm{~m}$ which is the result of 30 steps of gradual adjustment. The point cloud representing the interior of the cathedral is shown in Fig. 5. C.

During the mapping of the exterior, 10 ground control points (GCPs) (black-and-white checkerboards $0.3 \times 0.3 \mathrm{~m}$ ) were surveyed by the global navigation satellite systems (GNSS) using differential positioning with the real time kinematic method. The GNSS corrections were acquired from the network of base stations of the Slovak National Positioning Service (SKPOS) by a broad-band modem connection. Observation on the GCPs was performed using weighted averaging with an interval of 30 seconds at the site achieving 3-D accuracy of $0.017 \mathrm{~m}$ on average. GCPs were distributed around the cathedral (Fig. 1) and they were used to transform the PRCS coordinates of the terrestrial LiDAR point data into the S-JTSK National Coordinate System (EPSG code: 5514), so called global coordinate system (GLCS). Coordinate transformation into the GLCS was performed in two steps using Helmert transformation method (Fig. 3, P4). Firstly, the point cloud representing the exterior of the cathedral was transformed using the GCPs. When scanning the interior parts of the cathedral, two positions were placed at the western and southern portals so that the exterior parts of the cathedral were also captured and spatially overlapping with the data form the interior of the building. Subsequently, the point cloud representing the interior of the cathedral was matched to the point cloud of the exterior via planar patches found in the areas of overlap using the MSA tool. The procedure for using the MSA was the same as for the automatic alignment of the point clouds of the exterior parts described previously. This step ensures that data from all sources can be integrated into a single geodatabase with high accuracy. Standard deviation error of GLCS is $0.0278 \mathrm{~m}$.

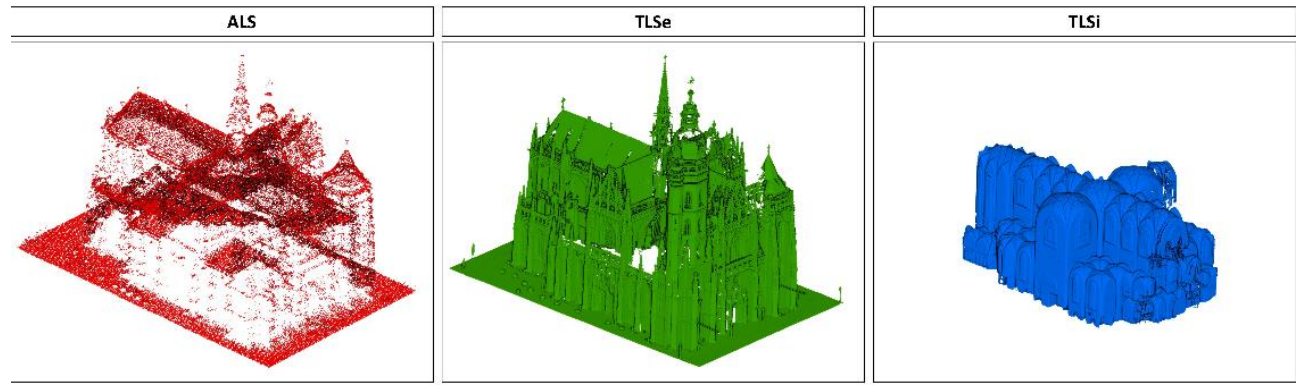

Fig. 5. Point clouds representing the exterior parts of the cathedral captured by airborne laser scanning $(A L S)$ and by terrestrial laser scanning (TLSe) and the interior parts of the cathedral from terrestrial laser scanning.

\section{Data filtering and classification}

Detecting noise points in point clouds with TLS is a complex task. For a variety of morphology, it was not possible to perform object classification in one step. For this reason, we performed the classification of TLS point clouds in several steps separately for point clouds representing the cathedral exterior and interior (Fig. 3, P5, Fig. 6). The approach was based on a step-by-step sequence where unambiguously identifiable points are graded by automatic filters. Manual classification of point clouds was performed in the last step.

In the first step, all points located within $2.5 \mathrm{~m}$ from the ground points were selected visually using side view as the noise as most of it occurred near the ground because the visitors 
were the main source of noise. The limiting height value also corresponds to the height just above the maximal human height. In the second step, the points representing the terrain were classified using the surface filter tool implemented in RiSCAN Pro software. The tool uses an algorithm that searches for continuous coplanar points at the altitude local minimum. The degree of coplanarity can be defined by the amplitude of the points in a search radius. Another important parameter is the maximum angle of inclination of the plane passing through coplanar points. In our case, the inclination of the planes was up to 5 degrees. In this way, we classified the terrain and floor of the cathedral in its interiors as ground.

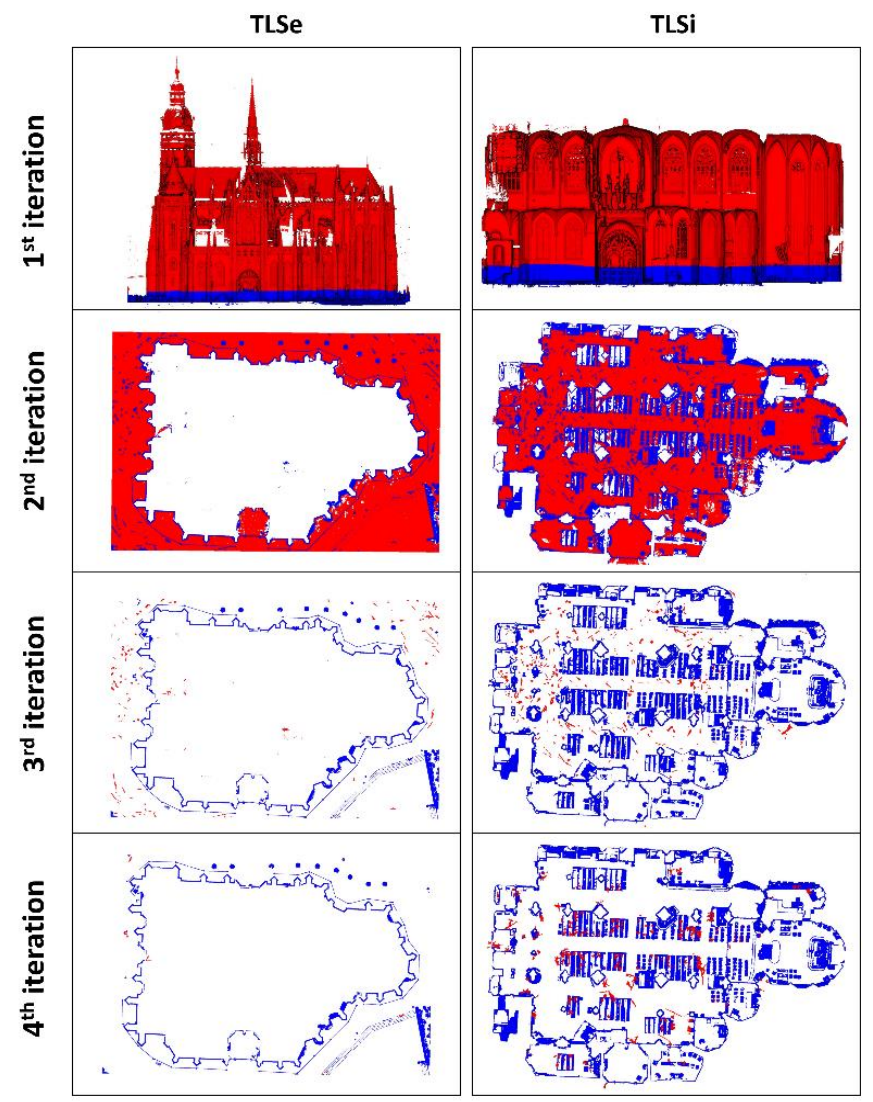

Fig. 6. Demonstration of the point clouds that entered to the individual steps in the denoising procedure. The red colour represents the points representing the already classified points, the blue colour represents the points that are the input to the next step.

The remaining points were classified as non-ground points and they were the input to the next step in which we applied the label connected components (LCC) tool implemented in the CloudCompare software (Girardeau-Montaut 2006). The LCC tool uses an algorithm that segments a point cloud into clusters. Clustering is based on searching for connected components. The user defines the minimum number of points that make up a cluster. The second important parameter is the maximum distance between the points within cluster. This is a point-to-point limit value that defines the maximum distance between points. In our case, one cluster consisted of at least 10 points and the distance between clusters was $0.1 \mathrm{~m}$. We opted for this method as it enables segmentation of the point cloud into related objects, i.e. point clusters, which greatly simplifies the manual point classification. In the final step of manual classification, the operator decided whether or not the point cluster is noise or it should remain in the dataset. 
The input point cloud in this study was composed of points without terrain points, therefore it is possible to identify continuous clusters of points that represent different objects such as walls, pillars, persons and others.

\section{Results and Discussion}

The achieved results are presented in the following two sections. At first, we focus on evaluating the classification of noise in the LiDAR point clouds by a combination of LCC filtering and manual classification. The second section focuses on the quality of integration of point clouds from multiple sources, i.e. airborne and terrestrial laser scanning, to generate a 3D model of the cathedral.

\section{Evaluation of the proposed gradual data filtering approach}

Generation of a 3-D model of the cathedral required integration of three kinds of point datasets collected by airborne and terrestrial laser scanning for the exterior and interior of the building (Tab. 1). The ALS mission was performed for a wider area of the historical city. The area of interest for this case study (AoI) (Fig. 1) comprised ca. 157,000 points.

Tab. 1. The number of points in point clouds in individual steps

\begin{tabular}{|c|c|c|c|c|}
\hline & Phase & ALS & TLSe & TLSi \\
\hline \multicolumn{2}{|c|}{$\begin{array}{l}\text { Raw data processing } \\
\text { of mutual scan positions }\end{array}$} & 157295 & 410025679 & 1623068704 \\
\hline \multicolumn{2}{|c|}{$\begin{array}{l}\text { Point spacing } \\
\text { after reduction }\end{array}$} & 157150 & 39127330 & 70470375 \\
\hline $1^{\text {st }}$ step & $\begin{array}{l}\leq 2,5 \mathrm{~m} \\
>2,5 \mathrm{~m}\end{array}$ & - & $\begin{array}{l}11629396 \\
27497934\end{array}$ & $\begin{array}{l}21185163 \\
49285212\end{array}$ \\
\hline $2^{\text {nd }}$ step & $\begin{array}{l}\text { Ground } \\
\text { Off ground }\end{array}$ & $\begin{array}{r}21575 \\
135575\end{array}$ & $\begin{array}{l}6728110 \\
4901286\end{array}$ & $\begin{array}{r}7962612 \\
13222551\end{array}$ \\
\hline $3^{\text {rd }}$ step & $\begin{array}{r}\text { Noise } \\
\text { Building/Not noise }\end{array}$ & $\begin{array}{l}37113 \\
98462\end{array}$ & $\begin{array}{r}194377 \\
4706593\end{array}$ & $\begin{array}{r}247719 \\
12974126\end{array}$ \\
\hline \multirow{2}{*}{$4^{\text {th }}$ step } & $\begin{aligned} \text { Noise } & \leq 2,5 \mathrm{~m} \\
\text { Not noise } & \leq 2,5 \mathrm{~m}\end{aligned}$ & - & $\begin{array}{r}46198 \\
4660395\end{array}$ & $\begin{array}{r}577190 \\
12396936\end{array}$ \\
\hline & $\begin{array}{r}\text { Noise }>2,5 \mathrm{~m} \\
\text { Not noise }>2,5 \mathrm{~m}\end{array}$ & - & $\begin{array}{r}174414 \\
27323836\end{array}$ & $\begin{array}{r}411777 \\
48901141\end{array}$ \\
\hline \multicolumn{2}{|c|}{ Total noise points } & 37113 & 414989 & 1236686 \\
\hline \multicolumn{2}{|c|}{ Final output } & 120037 & 38712341 & 69233689 \\
\hline
\end{tabular}

The original, raw point clouds contained redundant points. Thus, the original data was decimated to make the spatial distribution of points more even. Minimum spacing between points of $0.01 \mathrm{~m}$ was used for this task. In the case of ALS, however, there was a minimal reduction in the number of points. On other hand, the TLS data representing the exterior (TLSe) were considerably reduced from over 410 million points to just above 39 million points, thus by about $90 \%$. The reduction of the number of points was caused by the selection of points belonging to the AoI and by the harmonization of the spatial distribution of points to $0.01 \mathrm{~m}$. The TLSi data representing the interior of the cathedral were reduced by $95 \%$ for the same reasons as in the case of TLSe data. Thus, only $10 \%$ (TLSe) and 5\% (TLSi) of the points were used for the following data processing.

Despite the significant reduction in the number of points, the quality of the recorded geometry of the cathedral shapes did not deteriorate. The high point density of data collection is argued as follows. Point cloud density can be affected during the mapping process with (i) optimizing scanning positions, (ii) settings of scanning quality and (iii) selecting the scanning spatial section, respectively. We placed the scan positions within $10 \mathrm{~m}$ apart which increased the data volume and data overlaps between individual positions, but it had a positive impact 
on reducing the total internal registration error by using the matched planes outside the AoI in the mutual orientation of the spatially overlapping scans. In both cases (TLSe and TLSi), the standard deviation error of mutual orientation of the scans is deeply below $0.01 \mathrm{~m}$. The second reason for the densely spaced scanning positions was that mapping was done without closing the scanning area, increasing the probability of capturing individual parts of the scanned object and reducing the number of shadows in the final point clouds.

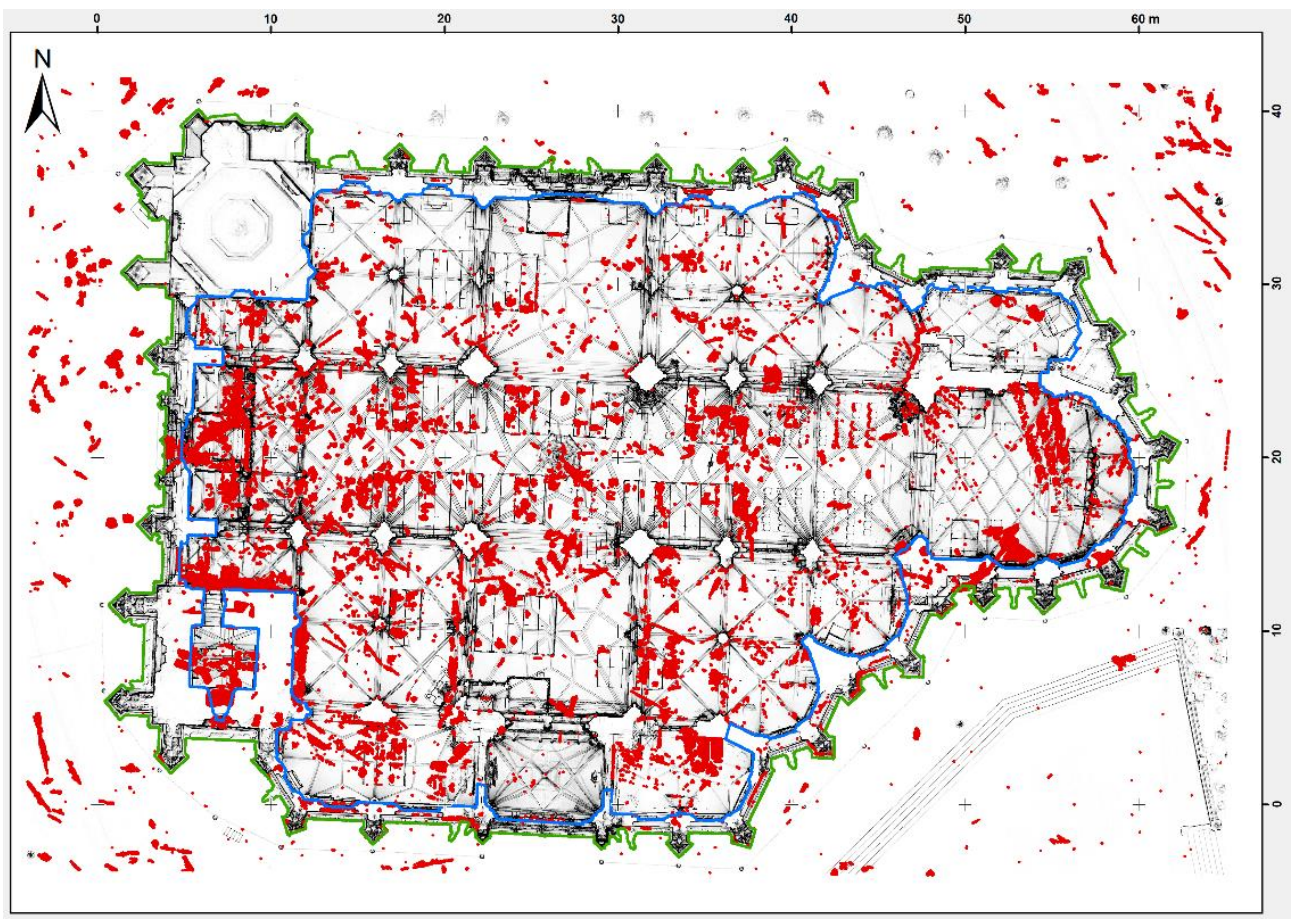

Fig. 7. Top-view visualization of the result of semi-automatic noise classification (red clusters of points) in cloud points from ground laser scanning shown. The blue line represents the inner and green the outer wall of the cathedral.

For TLSe and TLSi, the scan detail in the scanners was set so that the pulse was emitted every approximately 0.04 degrees of vertical and horizontal mirror rotation. Thus, we opted for the principle to get lower scanning density on one position, but scanning from more positions with larger overlaps between the scan positions. In order to reduce the mapping time at one position, all positions were scanned at a horizontal angle of 360 degrees. This is because the scan time at one position was approximately 3 minutes. If we had to manually define a field of view in the scanner settings for each position, the time would be longer. In addition, repeated measurements could also lead to errors that would affect the quality of coverage in the resulting point clouds. This scanning approach had a significant effect on the reduction of points especially in the exterior, where more than $60 \%$ of points represented objects outside the AoI. Thus, by harmonizing the spatial distribution of points within the AoI, we mainly reduced the redundant points due to the high overlap of the scan positions.

In the first step, we divided the TLS point clouds into two parts - above and below $2.5 \mathrm{~m}$. This was because the occurrence of humans as the unwanted point representations (noise) is only in the ground layer up to $2.5 \mathrm{~m}$ (Fig. 8).

The second step was focused on identification of points representing the terrain. The points up to the relative height level of $2.5 \mathrm{~m}$ above the visual and manually identified terrain were the input. The points that were classified as ground were automatically identified using the 
terrain filter tool in RiScan PRO. The terrain represents approximately 17\% of TLSe data and approximately $11 \%$ of TLSi data from point clouds. For ALS, the terrain representation points were identified by the lasground tool in LAStools and these represented approximately $14 \%$ of the total ALS points.

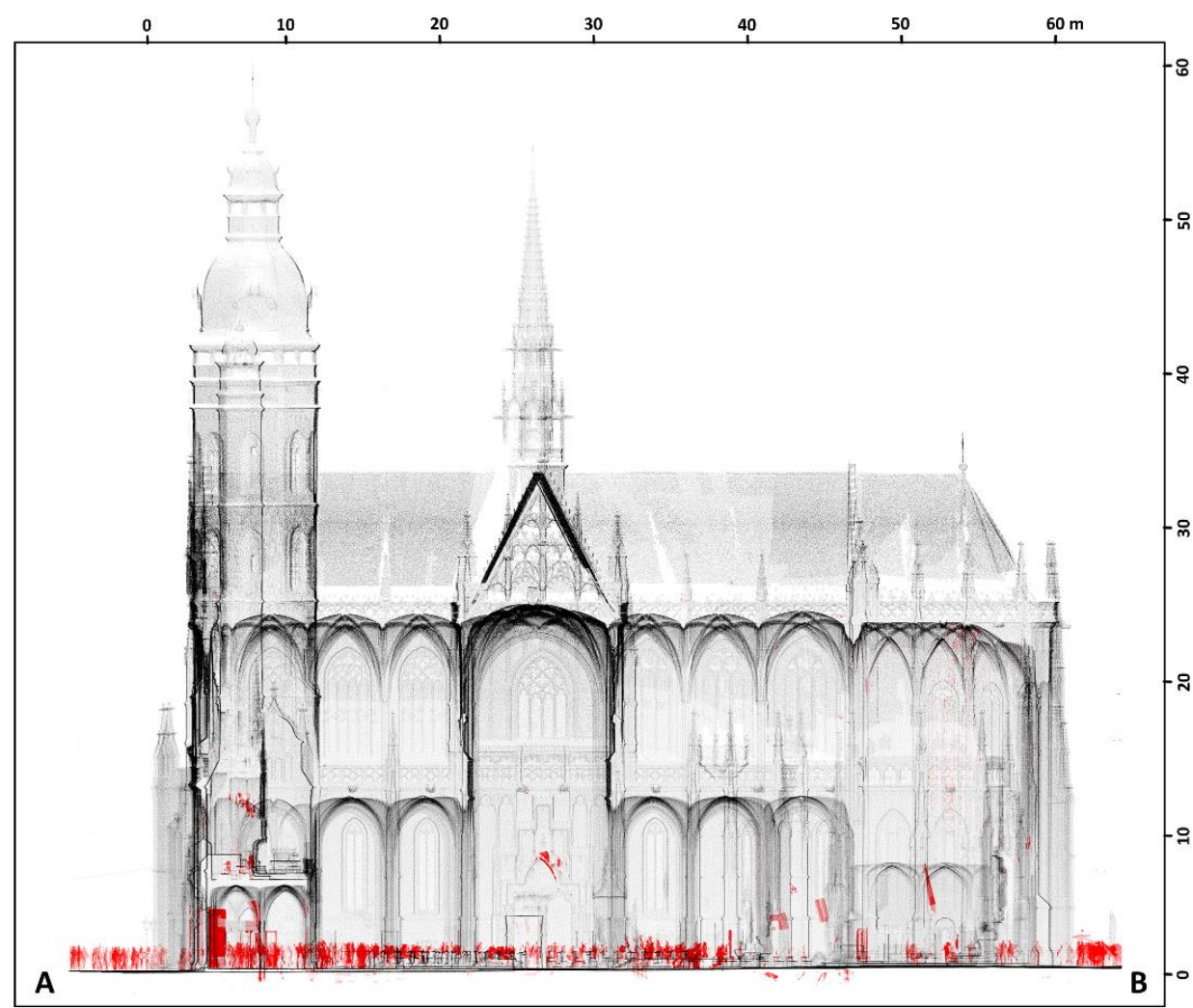

Fig. 8. Side-view visualization of the result of semi-automatic noise classification (red clusters of points) in point clouds from TLS. Most of the noise was caused by persons up to $2.5 \mathrm{~m}$ from the terrain.

The third step involved the automatic classification of points representing the noise. This step took approximately 30 minutes. Based on the presented LCC filter, we have identified up to $80 \%$ of the total noise in the point cloud up to $2.5 \mathrm{~m}$ in the exterior, as documented in Fig. 6. TLSe 3rd step. This method was less successful in interiors, where we classified only $30 \%$ of the noise from the total noise in the point cloud up to $2.5 \mathrm{~m}$. The points recorded on the people sitting in the pews caused problems with the classification of noise points. In case of these points, the maximum distance of the point representing noise was less than $0.1 \mathrm{~m}$ from the nearest cluster of points. Thus, the points representing noise were associated with the pew. As it can be seen in Fig. 6, TLSi 3rd step, we have identified up to 529 point clusters by LCC filter representing the noise. Thus, if a person sat in a pew, it could be recorded from multiple positions/from multiple sides. A moving person is represented by a smaller number of points in the point clouds compared to the static objects. The LCC filter captured the vast majority of individual clusters, which we considered to be noise, but the noise in the pews represented more points.

In the last step, only 29 point clusters were identified in the pews, reaching 577,190 points and representing noise. This manual point classification was the most time consuming task taking about 4 hours. In addition to the remains of noise from the previous step, noise was identified mainly around glass objects such as windows, lights, large-screen displays in the 
cathedral, showcases. These are the so-called stray points. The location of these objects was usually higher than $2.5 \mathrm{~m}$ above the terrain and their manual identification was unambiguous and time-consuming (within 10 minutes). Usually, these were large clusters with many points which were relatively easy to identify.

\section{Integration of multi-sources LiDAR point clouds}

After removing the noise points, point clouds from the individual scan missions were integrated into a common, single geodatabase with a common coordinate system (SJTSK - EPSG code: 5514). Integration of data from multiple sources was necessary to create a 3-D model of the cathedral. Our argument is supported by Fig. 9, which shows points representing the cathedral of ALS, TLSe and TLSi mapping in a vertical profile. The ALS point cloud captures the roof and roof terrace of the cathedral and adequately represents its morphology. However, the point density is sparse on the walls and small cathedral steeples. Compared to the TLS data, the ALS point cloud has the lowest point density, which is critical for capturing small roof objects, since it is no longer possible to distinguish the shape of cathedral decorative elements such as crosses, statuettes, decorative ledges, etc. Also, in the immediate vicinity of the cathedral, there are no points on the terrain, which is caused by the shape and direction of the flight lines during the flight mission. The second drawback of the ALS point cloud is that the points representing the planar surface have higher amplitude. This is due to the calculation of the trajectory of the orbit and the limit of accuracy of the inertial measurement of the position of the scanner device.

On the other hand, the TLSe point cloud very well represents the walls of the cathedral, the terrain near the cathedral, and its exposed roof sections. Fewer or no points were recorded in places on the roof obscured from the ground for the scanner's field of view. But the closer relative distance to the building allows for high point density and mapping accuracy than compared to ALS. In addition to improving the point representation on the exterior walls, several smaller objects were sampled in greater detail with TLSe. The TLS points representing different inclined planes have lower scattering, allowing the wall surface to be more accurately expressed. It turned out that it was necessary to combine points from ALS and TLSe to map the exterior of the cathedral. In the resulting point cloud representing the exterior of the cathedral, the point coverage capturing the building was sufficient without significant holes in the point cloud. The TLSi points capturing the interior of the cathedral in high detail represent a separate group.

The final point cloud originating from the integration of the ALS, TLSe, TLSi point data was used in the last step to generate a 3-D model of the cathedral. The digital model of the cathedral was created as a mesh using the Poisson surface reconstruction method implemented in the CloudCompare software with Octree level 14, representing a distance of $1.5 \mathrm{~cm}$, thus preserving a very high spatial detail (Fig. 10. A). As the camera was activated during scanning, the resulting 3-D model could be coloured with true colours based on acquired photographs. The scanning in the exterior of the cathedral was performed within one day, from 11:00 a.m. to 2:00 p.m. under clear sky and sunny weather conditions. Inevitably, the light conditions and shadows were changing during mapping for the relative movement of the Sun. These deficiencies are mainly seen in places where individual scan positions are overlapped. These are mainly places on the ground and exposed parts of the roof. To make the colour transition between photos smooth, it would be necessary to perform radiometric corrections. The created mesh 3-D model of the cathedral has lower quality in places where the density of points coverage was lower. It is a transition between wall and roof terrace. The ALS point cloud had a considerably lower point density and accuracy than the TLS data. However, with the TLS were not capable of mapping the roof and top parts of the building while the ALS method was. Therefore, we consider the lower quality ALS data suitable for creating a 3-D model the complete building than no data at all. Alternatively, digital image collection with a UAV could be used and methods of close-range photogrammetry with structure from motion approach deployed to derive a more detailed representation of the cathedral exterior. The legal and safe use of UAVs in the built up area would, however, require long preparation and safety measures, which in turn would increase the time for data acquisition. 

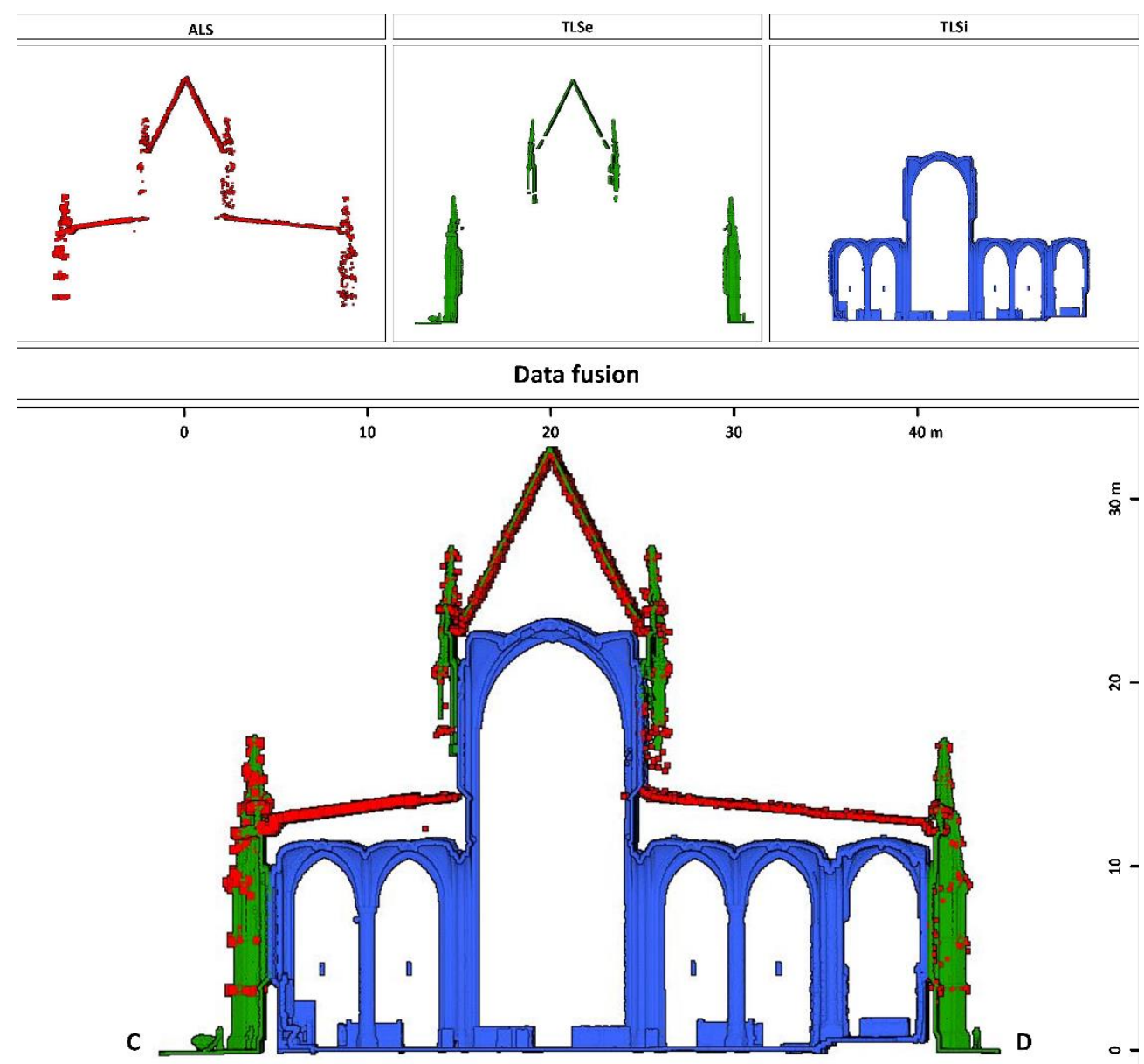

Fig. 9. Integration ALS, TLSe and TLSi point clouds to the single database. The place of the vertical profile is shown on the Fig. 1. C-D.

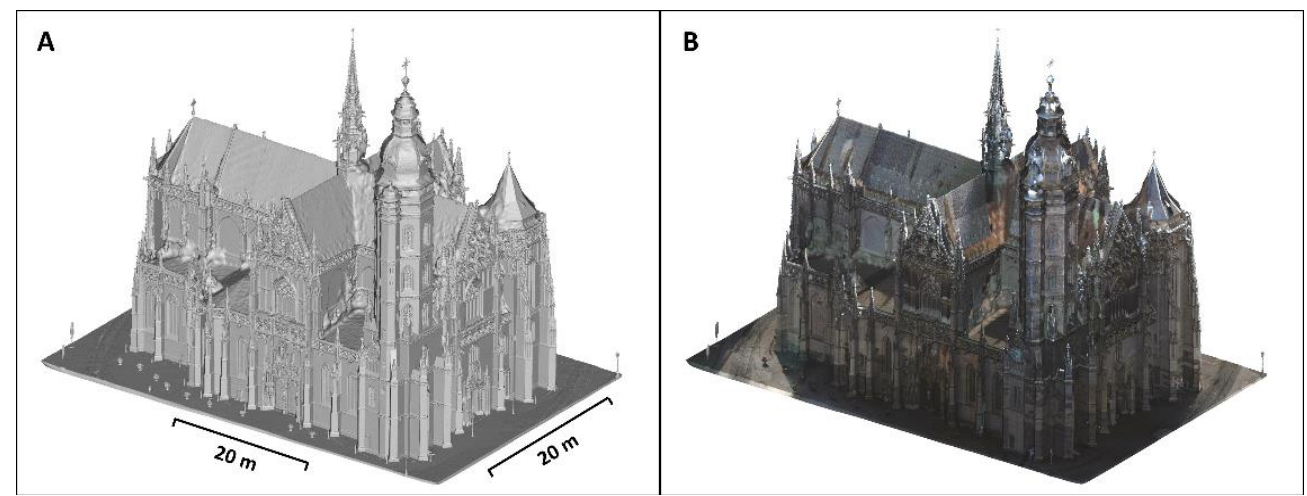

Fig. 10. 3-D model of the cathedral as (A) a mesh model and (B) colourised mesh model in true colours based on photographs. 
This deficiency could be improved by adding scan positions on the roof terrace, which is possible in case of the Cathedral of St. Elizabeth. High detail of the model was achieved on the cathedral roofs and towers, where the crosses and other decorative objects are originally scanned in high detail.

The mapping was carried out without restraining the public access in the exterior and interior parts of the cathedral. Therefore, data noise was inevitably introduced into the point clouds due to the presence of people in the scanner's line of sight. To eliminate the data voids, scan positions were placed closely to each other as would normally be needed. We assumed that the higher density of scanned positions will eliminate the data shadows in the resulting point cloud caused by moving persons. One approach of filtering the noise from 3-D point clouds is in selection (classification) of points manually (Gómez-Lende and Sánchez-Fernández 2017). The operator searches through the point cloud to identify objects that are consider noise. However, such a procedure is time-consuming. The second option is an automatic data classification procedure. Generally, it works based on a certain polynomial function by which a user defines particular properties of the searched object and the size of search radius (Han et al. 2017). However, the automatic classification carries the risk that due to the high variability of various object properties, it is not possible to classify all the searched objects correctly. In this respect, one of the greatest challenges is identifying noise in the data. In this study, we consider all points that represent wasteful objects needed for generating a 3-D cathedral model as a noise. Zhou et al. (2020) presented a promising procedure of denoising 3D point clouds which, however, was tested with randomly scattered 3D noise points. So this method needs to be tested with sharply defined objects, which are considered as unwanted in the scanned scene.

\section{Conclusions}

The multi-platform laser scanning technology enables mapping the urban space in a very fine resolution. This makes it possible to generate highly detailed 3-D models of buildings including their exterior and interior parts providing new capabilities in the Smart City concept. The combined use of sensors from airborne and terrestrial platforms overcomes the limitation of just airborne remote sensing data collection, which is the main method for creating 3-D city models in many countries including Slovakia. Complex morphology of historical buildings poses challenges to the solely airborne data acquisition. Taking the example of the St. Elisabeth Cathedral in the city of Košice, we demonstrated how the complex morphology of this gothic sacral building can be mapped in a high spatial resolution and surveying accuracy. Mapping cathedrals entails several challenges due to the complexity of their shapes, the variety of objects, the function, the cultural-historical value, the location and the need to record the interior and exterior as well. While airborne laser scanning was used for mapping the roof and surrounding objects from vertical to subvertical perspective, the terrestrial laser scanning was used to capture the exterior and interior of the cathedral from the ground. Normally, the public access around or into the cathedral would had to be blocked while performing the terrestrial laser scanning. The presence of people in the surveyed scene is undesirable because persons in the scanning area generate point data which is considered noise and also they obscure the object of interest and cause data shadows, thereby deteriorating the quality of the recording. We showed the approach which did not require such an uncomfortable measure during mapping as blocking the public access. We discussed the steps of internal registration and placement of point clouds in a common coordinate system, data classifications and 3-D modelling of the object. We developed a methodical procedure for creating a 3-D model of a sacral building of complex morphology by removing the noise points with an semi-automated approach. It comprises several steps because the noise in the data represents moving persons located near the terrain. In the first step, we identified points near the terrain, then the terrain was defined, and finally the noise was defined. We used the connected-component labelling method to remove the noise in the data automatically which captured approximately $80 \%$ of the data noise 
in total. The remaining noise points had to be filtered out manually by the operator. The presented procedure greatly facilitates the process of LiDAR data classification and filtration. The future research can explore the applicability of this method to point clouds generated by to other methods, e.g. close range photogrammetry and testing in other kinds of environments such as shopping malls, castles, or semi-natural urban environments such as parks. Exploring more robust and precise methods for analysing the feature structures of noisy point clouds would be also of interest.

\section{References}

AMORUSO, G., SALERNO, R. 2019: Cultural Landscape in Practice. Cham (Springer International Publishing).

BADENKO, V., ZOTOV, D., MUROMTSEVA, N., VOLKOVA, Y., CHERNOV, P. 2019: Comparison of Software for Airborne Laser Scanning Data Processing in Smart City Applications. ISPRS-International Archives of the Photogrammetry, Remote Sensing and Spatial Information Sciences, XLII-5/W2, 9-13. DOI: https://doi.org/10.5194/isprsarchives-XLII-5-W2-9-2019.

BONCZAK, B., KONTOKOSTA, C. E. 2019: Large-scale parameterization of 3-D building morphology in complex urban landscapes using airborne LiDAR and city administrative data. Computers, Environment and Urban Systems, 73, 126-142. DOI: https://doi.org/ 10.1016/j.compenvurbsys.2018.09.004.

BOUTSI, A. M., IOANNIDIS, C., SOILE, S. 2019: An Integrated Approach to 3-D Web Visualization of Cultural Heritage Heterogeneous Datasets. Remote Sensing, 11(21), 2508. DOI: https://doi.org/10.3390/rs11212508.

CIDLÍNSKA, L. 1975: Košický dóm: národná kultúrna pamiatka [Dome of Košice: national cultural monument]. Košice (Východoslovenské vydavatel'stvo).

CRACKNELL, A. P. 2017: UAVs: regulations and law enforcement. International Journal of Remote Sensing, 38(8-10), 3054-3067. DOI: https://doi.org/10.1080/01431161.2017.1302115.

FRAŠTIA, M., LIŠČÁK, P., ŽILKA, A. et al. 2019: Mapping of debris flows by the morphometric analysis of DTM: A case study of the Vrátna dolina valley, Slovakia. Geographical journal, 71(2), 101-120. DOI: https://doi.org/10.31577/geogrcas.2019.71.2.06.

FRITSCH, D., KLEIN, M. 2018: 3-D preservation of buildings - Reconstructing the past. Multimedia Tools and Applications, 77(7), 9153-9170.

FRYSKOWSKA, A., STACHELEK, J. 2018: A no-reference method of geometric content quality analysis of 3-D models generated from laser scanning point clouds for hBIM. Journal of Cultural Heritage, 34, 95-108. DOI: https://doi.org/10.1016/j.culher.2018.04.003.

GIRARDEAU-MONTAUT, D. 2006: Detection de Changement sur des Données Géométriques $3 D$-doctoral thesis. Paris (Signal and Image processing, Telecom).

GÓMEZ-LENDE, M., SÁNCHEZ-FERNÁNDEZ, M. 2018: Cryomorphological Topographies in the Study of Ice Caves. Geosciences, 8(8), 274. DOI: https://doi.org/ 10.3390/geosciences8080274.

HAN, X. F., JIN, J. S., WANG, M. J., JIANG, W., GAO, L., XIAO, L. 2017: A review of algorithms for filtering the 3-D point cloud. Signal Processing: Image Communication, 57, 103-112. DOI: https://doi.org/10.1016/j.image.2017.05.009.

KAŇUK, J., GALLAY, M., ECK, C., ZGRAGGEN, C., DVORNÝ, E. 2018: Technical Report: Unmanned Helicopter Solution for Survey-Grade Lidar and Hyperspectral Mapping. Pure and Applied Geophysics, 175(9), 3357-3373. DOI: https://doi.org/10.1007/ s00024-018-1873-2.

LI, Y., TONG, G., DU, X., YANG, X., ZHANG, J., YANG, L. 2019: A Single Point-Based Multilevel Features Fusion and Pyramid Neighborhood Optimization Method for ALS Point Cloud Classification. Applied Sciences, 9(5), 951. DOI: https://doi.org/10.3390/app9050951.

LUO, L., WANG, X., GUO, H. et al. 2019: Airborne and spaceborne remote sensing for archaeological and cultural heritage applications: A review of the century (1907 - 2017). Remote 
Sensing of Environment, 232, 111280. DOI: https://doi.org/10.1016/ j.rse.2019.111280.

MARTIN, N. 2019: Digital scans and data could help restore Notre Dame after fire. Forbes, AI \& Big Data [cit. 2019-12-09]. Retrieved from: https://www.forbes.com/sites/nicolemartin1/ 2019/04/16/digital-scans-and-data-could-help-restore-notre-dame-after-fire/\#5272c1-8b630b.

MARTÍNEZ-CARRICONDO, P., CARVAJAL-RAMÍREZ, F., YERO-PANEQUE, L., AGÜERA-VEGA, F. 2019: Combination of nadiral and oblique UAV photogrammetry and HBIM for the virtual reconstruction of cultural heritage. Case study of Cortijo del Fraile in Níjar, Almería (Spain). Building Research \& Information, 1-20. DOI: https://doi.org/10.1080/09613218.2019.1626213.

MONEGO, M., MENIN, A., FABRIS, M., ACHILLI, V. 2019: 3-D survey of Sarno Baths (Pompeii) by integrated geomatic methodologies. Journal of Cultural Heritage, 40, 240 246. DOI: https://doi.org/10.1016/j.culher.2019.04.013.

MONNET, J. M., GINZLER, C., CLIVAZ, J. C. 2016: Wide-Area Mapping of Forest with National Airborne Laser Scanning and Field Inventory Datasets. International Archives of the Photogrammetry, Remote Sensing and Spatial Information Sciences, XLI-B8, 8, 727731. DOI: https://doi.org/10.5194/isprs-archives-XLI-B8-727-2016.

MOON, D., CHUNG, S., KWON, S., SEO, J., SHIN, J. 2019: Comparison and utilization of point cloud generated from photogrammetry and laser scanning: 3-D world model for smart heavy equipment planning. Automation in Construction, 98, 322-331. DOI: https://doi.org/ 10.1016/j.autcon.2018.07.020.

NOVO-FERNÁNDEZ, A., BARRIO-ANTA, M., RECONDO, C., CÁMARA-OBREGÓN, A., LÓPEZ-SÁNCHEZ, C. A. 2019: Integration of National Forest Inventory and Nationwide Airborne Laser Scanning Data to Improve Forest Yield Predictions in North-Western Spain. Remote Sensing, 11(14), 1693. DOI: https://doi.org/10.3390/rs11141693.

ONAČILLOVÁ K., KAŇUK J. 2016: Porovnanie interpretačných metód digitálnej fotogrametrie pre tvorbu 3D modelov budov pre úroveň LOD 2. Geographia Cassoviensis, $10(1), 70-81$.

PIROTTI, F., ZANCHETTA, C., PREVITALI, M., DELLA TORRE, S. 2019: Detection of building roofs and facades from airborne laser scanning data using deep learning. In 2nd International Conference of Geomatics and Restoration, GEORES 2019 (Vol. 42, No. 2, pp. 975-980). Copernicus GmbH. DOI: https://doi.org/10.5194/isprs-archives-XLII-2-W11-975-2019.

ŠAŠAK, J., GALLAY, M., KAŇUK, J., HOFIERKA, J., MINÁR, J. 2019: Combined use of terrestrial laser scanning and UAV photogrammetry in mapping alpine terrain. Remote Sensing, 11(18), 2154. DOI: https://doi.org/10.3390/rs11182154.

ŠUPINSKÝ, J., KAŇUK, J., HOCHMUTH, Z., GALLAY, M. 2019: Detecting dynamics of cave floor ice with selective cloud-to-cloud approach. The Cryosphere, 13, 2835-2851. DOI: https://doi.org/10.5194/tc-13-2835-2019.

THWAITES, H., SANTANO, D., ESMAEILI, H., SEE, Z. S. 2019: A Malaysian cultural heritage digital compendium. Digital Applications in Archaeology and Cultural Heritage, 15, e00116. DOI: https://doi.org/10.1016/j.daach.2019.e00116.

ULLRICH, A., PFENNIGBAUER, M. 2019: Advances in lidar point cloud processing. SPIE Proceedings - Laser Radar Technology and Applications XXIV, 11005. DOI: https://doi.org/10.1117/12.2518856.

ULLRICH, A., SCHWARZ, R., KAGER, H. 2003: Using hybrid multi-station adjustment for an integrated camera laser-scanner system, Optical 3-D Measurement Techniques, IV(1), 298-305.

VAŠKO, I. a kol. 2000: Dóm svätej Alžbety v Košiciach [St. Elisabeth Cathedral in Košice]. Košice (Sáša).

YANG, B., LEE, J. 2019: Improving accuracy of automated 3-D building models for smart cities. International journal of digital earth, 12(2), 209-227. DOI: https://doi.org/10.1080/ 17538947.2017.1395089.

ŽÁRY, J. 2011: Severný portál Dómu sv. Alžbety v Košiciach [North Portal of St. Dome's Cathedral Elizabeth in Kosice]. Pamiatky a múzeá, 3, 32-39 (in Slovak). 
Acknowledgement: This work was supported by the Slovak Research and Development Agency under the contract no. SK-CN-RD-18-0015 and Scientific Grant Agency of the Ministry of Education, science, research and sport of the Slovak Republic and the Slovak Academy of Sciences no. VEGA 1/0839/18.

\author{
Authors' affiliations \\ doc. RNDr. Ján Kaňuk, PhD. \\ Institute of Geography \\ Faculty of Science \\ Pavol Jozef Šafárik University in Košice \\ Jesenná 5 \\ 04001 Košice \\ Slovak Republic \\ jan.kanuk@upjs.sk
}

\author{
Mgr. Jozef Šupinský \\ Institute of Geography \\ Faculty of Science \\ Pavol Jozef Šafárik University in Košice \\ Jesenná 5 \\ 04001 Košice \\ Slovak Republic \\ jozef.supinsky@upjs.sk
}

\title{
Mgr. Ján Šašak
}

Institute of Geography

Faculty of Science

Pavol Jozef Šafárik University in Košice

Jesenná 5

04001 Košice

Slovak Republic

jan.sasak@upjs.sk

prof. Mgr. Jaroslav Hofierka, PhD.

Institute of Geography

Faculty of Science

Pavol Jozef Šafárik University in Košice

Jesenná 5

04001 Košice

Slovak Republic

jaroslav.hofierka@upjs.sk

prof. Ing. Vladimír Sedlák, PhD.

Institute of Geography

Faculty of Science

Pavol Jozef Šafárik University in Košice

Jesenná 5

04001 Košice

Slovak Republic

vladimir.sedlak@upjs.sk 
doc. Mgr. Michal Gallay, PhD.

Institute of Geography

Faculty of Science

Pavol Jozef Šafárik University in Košice

Jesenná 5

04001 Košice

Slovak Republic

michal.gallay@upjs.sk

Mgr. Katarína Onačillová

Institute of Geography

Faculty of Science

Pavol Jozef Šafárik University in Košice

Jesenná 5

04001 Košice

Slovak Republic

katarina.onacillova@upjs.sk

\section{Dr. Yongbo Wang}

School of Environment Science and Spatial Informatics

China University of Mining and Technology

Daxue Road NO.1

221116 Xuzhou

People's Republic of China

ybwang@cumt.edu.cn

\section{Dr. Qiuzhao Zhang}

School of Environment Science and Spatial Informatics

China University of Mining and Technology

Daxue Road NO.1

221116 Xuzhou

People's Republic of China

qiuzhao.zhang@cumt.edu.cn 